\title{
Radiocirurgia: a solução para uma doença de difícil tratamento?
}

\author{
Radiosurgery: a solution to a difficult disease treatment?
}

\begin{abstract}
Efectividad del tratamiento con bisturí de rayos gamma en pacientes afectados por la neuralgia del trigémino idiopática recurrente, de Amutio Gutiérrez S e Soto-González M. Neurología: 1-9p, vol. 30, n.20, 2014. http://dx.doi.org/10.1016/j.nrl.2014.02.006.
\end{abstract}

MARIANE SOTORIVA

Graduanda do Curso de Odontologia (FOL/UNIMEP)

Entre as algias faciais, mais comuns em mulheres e de idade avançada, a neuralgia de trigêmio ocupa lugar de destaque, tendo em vista que pode incidir em 15 a 100 casos a cada 100.000 habitantes, no mundo. Como o trigêmio é subdividido em três ramos: o oftálmico, o maxilar e mandibular, observase que o maxilar e mandibular são os mais envolvidos, afetando a região e tendo um fator desencadeante. A dor é contínua e lancinante e pode se estender por períodos longos ou esparsos, porém produzem grande sofrimento aos seus portadores.

Aetiologia é discutida e bem variável: desde uma compressão vascular na raiz do nervo a uma desmielinização que resulta em uma hipersensibilidade do mesmo. Entretanto, o que se percebe é que quando instalada a doença, lidar com ela se torna bastante complexo e pode exigir um tratamento multidisciplinar, envolvendo área médica, odontológica, psicológica e por vezes até psiquiátrica.

Uma escala é utilizada para graduar a sintomatologia dolorosa em relação ao estadiamento da mesma: Barrow Neurological Institute Pain Intensity Scale (BNI)- a Escala de Intensidade de Dor do Instituto Neurológico de Barrow. Enquanto que os Graus I e II não necessitam de tratamento, do grau IIIA ao Grau $\mathrm{V}$, os pacientes apresentam dor que pode ser minimizada ou não por medicamentos.

O tratamento medicamentoso preconizado na América do Norte e Europara baseia- se na carbamazepina, fenitoína, baclofeno ou gabapentina. No Brasil utiliza-se, na Estomatologia, tratamentos iniciais com vitamina B12 em altas doses injetáveis, tendo em vista seu potencial neuroregenerador. Em segunda instância associa-se o que é preconizado também pela Sociedade Brasileira de Neurologia, tal qual citado, porém com tratamento multidisciplinar incluindo o neurologista. Finalmente, no Grau V e sem melhora do quadro sintomatológico pode-se optar pelo tratamento cirúrgico que pode ser realizado como uma rizotomia por frequência percutânea, ou descompressão microvascular ou rizotomia retrogasseriana com glicerol, mas a partir de 1953 foi preconizado uso do bisturi de raios gama. Essa técnica consiste em direcionar seletivamente raios gama, provenientes de uma fonte radioativa de cobalto.

Como todo tratamento, o bisturi de raios gama, pode ser efetivo e produzir controle da dor em alguns casos e em menores graus, porém em casos severos pode produzir efeitos adversos a serem considerados. A técnica deve ser orientada por exames imaginológicos (Tomografia Computadorizada Cônica, Tomografia por Emissão de pósitron ou Ressonância Magnética), que detectem um ponto central, isocêntrico, específico para a irradiação com raios gama, exigindo precisão para seu uso.

O trabalho consiste em uma revisão de literatura sobre o assunto em três bases de da- 
dos (Scopus, Medline e CINAHL) em um total de 16 artigos. O resultado obtido referiu resultados mais ou menos eficientes segundo a zona irradiada, número de isocentros. Quanto às doses estas foram mais efetivas no controle da dor quando utilizou-se um espectro menor de radiação em valores altos (70-90 Gy), ou seja quanto maior a dose, melhor o resultado, porém a possibilidade de complicações como tumefação facial e parestesia também foram mais evidentes.

Fica bem evidente que esse tipo de tratamento, como os demais na neuralgia de trigêmio oferece, em alguns casos melhoras por um tempo, recorrências em períodos variados.
A disfunção sensitiva é uma das complicações claras evidenciadas neste tipo de tratamento.

O tratamento com bisturi de raios gama é considerado como uma última opção, principalmente em casos onde outros procedimentos, inclusive cirúrgicos não foram bem sucedidos.

As vantagens? São abordadas como procedimento ambulatorial, paciente desperto e sem necessidade de anestesia.

O que se percebe, contudo é que os critérios de sucesso e insucesso são muito variáveis e o número de trabalhos ainda insuficientes para garantir eficácia deste tipo de tratamento. Apesar do tempo de utilização deste tipo de tratamento não se pode dizer que é efetivo. Se efetivo pode causar efeitos adversos severos. 